\title{
Congenital Mirror Movements in Gorlin Syndrome: A Case Report With DTI and Functional MRI Features
}

Erdal Sag, MD, ${ }^{a}$ Rahsan Gocmen, MD, ${ }^{b}$ F. Gokcem Yildiz, MD, ${ }^{c}$ Zeynelabidin Ozturk,

MD, ${ }^{a}$ Cagri Temucin, MD, PhD, ${ }^{d}$ Ozlem Teksam, MD, ${ }^{a}$ Eda Utine, MDe

Congenital mirror movements are rare conditions that define the inability to perform unimanual movements. Gorlin syndrome, also known as nevoid basal cell carcinoma syndrome, is a genetic disorder with multiple nevi predisposing to basal cell carcinoma, odontogenic keratocysts, and skeletal malformations. Herein we report on an adolescent patient with Gorlin syndrome and coexisting congenital mirror movements. To our knowledge, this is the first patient in the literature who has both of these very rare conditions.

Congenital mirror movements are rare conditions characterized by the inability to perform unimanual movements and unintentional mirroring of voluntary movements on the opposite side of the body, mainly at the upper extremity. ${ }^{1}$ This phenomenon is usually isolated, which means that it is not part of a syndrome, or it may be syndromic as a component of several conditions such as Kallmann syndrome, KlippelFeil syndrome, Joubert syndrome, Moebius syndrome, and congenital hemiplegia, ${ }^{2-5}$ and individual patients with Seckel syndrome and Wildervanck syndrome have also been reported with this condition. ${ }^{6-9}$ However, to our knowledge, this disorder was not previously described in patients with Gorlin syndrome.

Gorlin syndrome, also known as nevoid basal cell carcinoma syndrome, is an autosomal dominant disorder characterized by multiple basal cell carcinomas, jaw keratocysts, and skeletal malformations. ${ }^{10}$ The syndrome is a cancer-prone condition, which may predispose to, in addition to basal cell carcinomas of the skin, malignant or benign tumors such as medulloblastoma, uterine and ovarian fibromas/fibrosarcomas, meningioma, and cardiac fibromas. ${ }^{11}$ Herein, an adolescent patient with Gorlin syndrome and coexisting congenital mirror movements is reported as the first patient in the literature, to the best of our knowledge, who has both conditions.

\section{PATIENT PRESENTATION}

\section{A 16-year-old right-handed male} patient was referred to the pediatric outpatient clinic by his dentist with the radiologic finding of multiple odontogenic cysts. Past medical history revealed his inability to perform unimanual hand movements, starting from early infancy. His birth was uneventful as the second child of healthy nonconsanguineous parents. There was no familial history of any neurologic disease, odontogenic keratocysts, basal cell carcinomas, or any other significant disorder. Growth parameters and developmental milestones were normal.

Physical examination revealed short stature (height of $153 \mathrm{~cm}$, below the third centile), macrocephaly (head

\section{abstract}

\author{
$\left(\frac{10}{20}\right.$
}

Departments of a Pediatrics, ${ }^{b}$ Radiology, ${ }^{d}$ Neurology, and ePediatric Genetics, and ${ }^{c}$ Institute of Neurologic Science and Psychiatry, Hacettepe University, Ankara, Turkey

Dr Sag followed the patient as the primary doctor, drafted the initial manuscript, and revised and finalized the manuscript; Dr Gocmen performed the radiologic analysis; Drs Yildiz and Temucin conducted the electrophysiologic studies; Dr 0zturk took the photos and video of the patient and drafted the initial manuscript with Dr Sag; Dr Teksam followed the patient as the primary doctor with Dr Sag, coordinated and supervised data collection, and revised and reviewed the manuscript; Dr Utine diagnosed the patient with Gorlin syndrome, coordinated and supervised data collection, and critically reviewed the manuscript; and all authors approved the final manuscript as submitted

DOI: $10.1542 /$ peds.2015-1771

Accepted for publication Nov 23, 2015

Address correspondence to Erdal Sag, MD, Hacettepe Universitesi Ihsan Dogramaci Cocuk Hastanesi Pediatri Basasistanligi, 06230 Sihhiye, Ankara, Turkey. E-mail: sag.erdal@gmail.com PEDIATRICS (ISSN Numbers: Print, 0031-4005; Online, 1098-4275).

Copyright (C) 2016 by the American Academy of Pediatrics

FINANCIAL DISCLOSURE: The authors have indicated they have no financial relationships relevant to this article to disclose.

FUNDING: No external funding.

POTENTIAL CONFLICT OF INTEREST: The authors have indicated they have no potential conflicts of interest to disclose.

To cite: Sag E, Gocmen R, Yildiz FG, et al. Congenital Mirror Movements in Gorlin Syndrome: A Case Report With DTI and Functional MRI Features. Pediatrics. 2016;137(3):e20151771 
circumference of $58 \mathrm{~cm}$, above the 97th centile), incomplete unilateral cleft lip, coarse facial characteristics with prominent eyebrows, and mild hypertelorism. He also had multiple nevi over the trunk, Sprengel deformity, mild pectus deformity, and mild scoliosis, as well as a few palmar pits (Fig 1). Neurologic examination was normal except for the bilateral mirror movements of the hands (Supplemental Video).

On chest radiograph, there were 3 bifid costae, including fourth costa on the left, third and fifth costae on the right. Skull radiograph revealed multiple mandibular odontogenic keratocysts and supernumerary teeth (Fig 1). Neurophysiologic assessment with the WISC-R (Wechsler Intelligence Scale for Children-revised edition)revealed a verbal IQ of 62 and a performance IQ of 101, with an overall IQ of 80. The evaluation of family members for features of Gorlin syndrome and congenital mirror movements revealed negative results. The structure and function of the brain were evaluated with structural MRI, diffusion tensor imaging (DTI), functional MRI (fMRI), and electrophysiologic tests such as transcranial magnetic stimulation (TMS), as described below.

\section{Imaging Studies}

Structural MRI, DTI, and fMRI were performed with the use of a 3.0 Tesla magnet (Philips Healthcare, Ingenia, Netherlands). Structural MRI showed a left anterior temporal arachnoid cyst and bilateral hippocampal incomplete rotation. fMRI with blood oxygen level-dependent protocol data was acquired with a slice thickness of $4 \mathrm{~mm}$ without gap; a $128 \times 128$ acquisition matrix; a 23 -cm field of view; repetition and echo times of 3000 and 35 milliseconds, respectively; and with a "high force hand clenching test" for 240 seconds. fMRI data were obtained by subtracting the
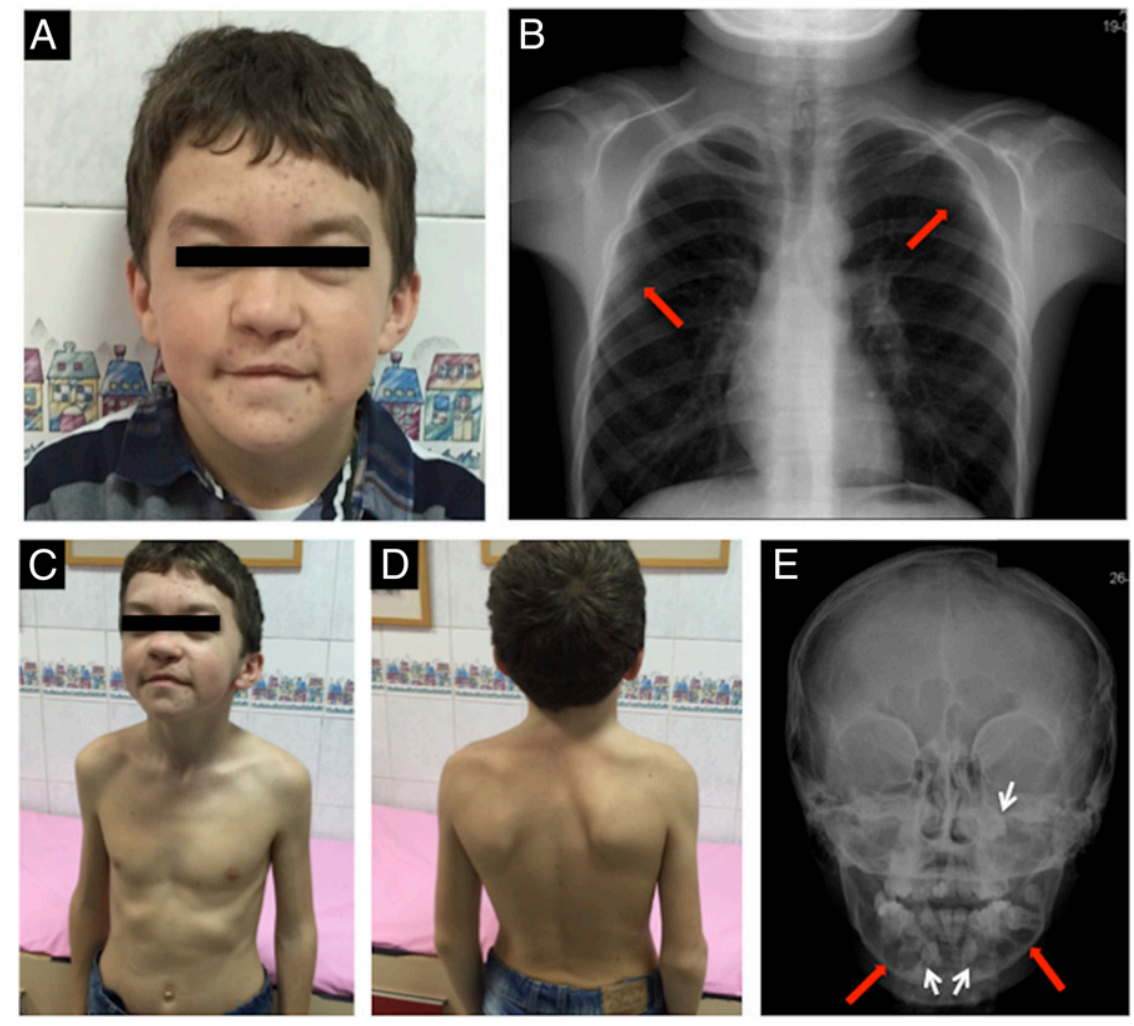

FIGURE 1

A, An incomplete left unilateral cleft lip, coarse face with thick eyebrows, minimal frontal bossing, and mild hypertelorism are shown. B, Posteroanterior chest radiograph showing a bifid fourth rib on the left, a fifth rib on the right (arrows), and right high scapula (Sprengel deformity). C and D, Multiple small nevi on the trunk are shown. E, Skull radiograph showing odontogenic keratocyts in the mandibula (red arrows) and mandibular and maxillary supernumerary and unerupted teeth (white arrows).

motor activity periods from the rest periods. All functional images were then coregistered with the subject's anatomic images. DTI data were acquired with 30 diffusion-encoding directions; $5.0-\times 5.0-\times 5.0-\mathrm{mm}$ isotropic voxel resolution; a $160 \times$ 160 acquisition matrix; repetition and echo times of 2065 and 92 milliseconds, respectively; and a $\mathrm{b}$-value of 800 seconds $/ \mathrm{mm}^{2}$. DTI fiber tracking showed a lack of the decussation of bilateral corticospinal tracts at the medulla oblongata (Fig 2A). fMRI showed bilateral activation in the precentral gyri and supplementary motor areas during both an ipsilateral and a contralateral hand-clenching task (Fig 2 B and C).

\section{Electrophysiologic Examinations}

To identify the motor organization of mirror movements, we studied motor pathways by using focal TMS. TMS was performed with parabolic coil connected Magstim (MagPro-stimulator, Medtronic A/S, Copenhagen, Denmark) with the TMS coil placed over the motor cortex (M1), motor-evoked potentials (MEPs) were obtained from ipsi- and contralateral relaxed abductor digiti minimi (ADM) muscles simultaneously by surface Ag-AgCl electrodes. MEP signals were amplified and filtered (20-2000 Hz). In cortical stimulation, we measured the cortical motor latency and MEP amplitudes. The MEP amplitude was measured from 100\% stimulator output during rest. An average of 3 trials was used to analyze MEP amplitude and latency. To measure cortical latency, we calculated the onset of averaged MEPs and obtained 


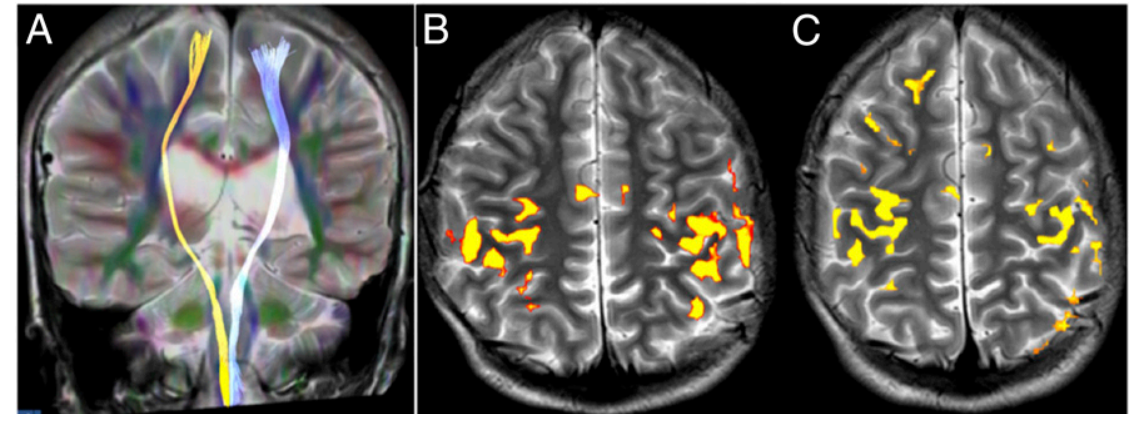

FIGURE 2

A, DTI fiber tractography images show lack of the decussation of bilateral corticospinal tracts. B, Blood oxygen level-dependent fMRI image shows activation of bilateral, symmetrically precentral and postcentral gyrus and supplementary motor area during a right-hand clenching task. C, Blood oxygen level-dependent fMRI image shows bilateral, asymmetrically precentral and postcentral gyrus and supplementary motor area activation during a left-hand clenching task.

the averaged response of amplitude values.

The left focal TMS evoked an ipsilateral MEP of ADM muscle (latency: 19.3 milliseconds; amplitude: $0.7 \mathrm{mV}$ ). However, there was a smaller MEP on the contralateral ADM muscle (latency: 22.8 milliseconds; amplitude: 0.2 $\mathrm{mV}$ ). Similarly, right TMS of the right hemisphere evoked ipsilateral MEPs from the ADM muscle (latency: 18.9 milliseconds; amplitude: $0.8 \mathrm{mV}$ ) and small contralateral MEPs (latency: 22.1 milliseconds; amplitude: $0.3 \mathrm{mV}$ ). On the basis of these neurophysiologic findings, it can be hypothesized that most corticospinal axons do not cross the midline but travel ipsilaterally.

\section{DISCUSSION}

Congenital mirror movements represent an interesting, rare congenital condition, which may persist into adulthood and are usually isolated. Although dominant and recessive inherited mutations in a few genes have been identified recently, these are present in only a minority of the patients and the genetic etiology remains to be elucidated in most of the cases. Several rare syndromes are known to accompany congenital mirror movements in a small subset of patients, with unclear molecular and genetic implications. Until now, to not been reported in a patient with Gorlin syndrome.

The present patient had some features of Gorlin syndrome, including facial and cranial findings, costal anomalies, borderline pits. However, it was the detection of mandibular odontogenic keratocysts that prompted the clinical consideration of a syndromic condition. Odontogenic keratocysts are one of the common presentations of the disease, most often encountered in adolescents. A wide range of developmental abnormalities including some skeletal abnormalities may coexist; however, a predisposition to neoplasms including basal cell carcinomas is usually the main concern. ${ }^{10,12,13}$ Other manifestations of the disease include hyperkeratosis of palms and soles, skeletal abnormalities (rib, vertebral column, skull, and extremities), intracranial ectopic calcifications, and craniofacial dysmorphic features including macrocephaly, cleft lip/palate, severe eye anomalies, and, in some patients, intellectual disability. ${ }^{12}$

The prevalence of Gorlin syndrome has been reported to range between 1 in 56000 and 1 in our knowledge, this condition has intellectual disability, and palmar
256000 in different studies, with a male to female ratio of $1: 1.5,14$ The molecular pathogenesis of Gorlin syndrome is attributed to mutations in the PTCH1 gene at $9 \mathrm{q} 22.3 \mathrm{q} 31.15,16$ However, the diagnosis is mostly clinical and requires the presence of 2 major or 1 major and 2 minor criteria. ${ }^{17}$ Major criteria include the following: (1) >2 basal cell carcinomas or 1 basal cell carcinoma under the age of 20 years; (2) odontogenic keratocysts proven by histopathology; (3) $\geq 3$ palmar or plantar pits; (4) bilamellar calcification of the falx cerebri; (5) bifid, fused, or splayed ribs; (6) a first-degree relative with the condition. Minor criteria include (1) macrocephaly after adjustment for height; (2) congenital malformations including cleft lip or palate, frontal bossing, coarse facies, or moderate to severe hypertelorism; (3) skeletal abnormalities including Sprengel deformity, pectus deformity, or syndactyly; (4) radiologic abnormalities including bridging of the sella turcica; vertebral anomalies such as hemivertebrae, fusion, or elongation of the vertebral bodies; modeling defects of the hands and feet; or flameshaped radiolucencies of the hands or feet; (5) ovarian fibroma; and (6) medulloblastoma. The present patient met 3 major (odontogenic keratocysts of the jaw, palmar pits, and bifid ribs) and 3 minor (macrocephaly and congenital malformations such as cleft lip, coarse face, hypertelorism, and Sprengel deformity) criteria.

Congenital mirror movements are rare conditions characterized by the inability to perform unimanual movements and unintentional mirroring of voluntary movements on the opposite side of the body. ${ }^{1}$ It is often nonsyndromic and persists through adulthood with no other associated abnormalities, or rarely, 
it may be a component of several syndromes. $^{2-5}$ Congenital mirror movements usually affect the distal upper extremities, especially the muscles that control the fingers. Mutations in 3 genes, $D C C, R A D 51$, and DNAL4, are known to be responsible for the disorder. ${ }^{1}$ The DCC gene encodes the DCC protein, a receptor for Netrin-1, which guides the axons across the midline of the body. ${ }^{18}$ The RAD51 gene product is thought to affect the development of corticospinal axons at the pyramidal decussation. ${ }^{19}$ An underlying genetic defect may be revealed in only a minority of affected individuals and the pathogenesis is better understood by TMS, DTI, and fMRI. An abnormal decussation of the corticospinal tract, abnormal interhemispheric inhibition and bilateral cortical activation of primary motor areas during intended unimanual movements, and an abnormal involvement of the supplementary motor area during both unimanual and bimanual movements are the 3 possible mechanisms. ${ }^{19}$ TMS and DTI revealed the presence of the first phenomenon, and fMRI revealed the presence of the second and third phenomena in the present patient.

The neurologic involvement in Gorlin syndrome usually manifests with ectopic calcifications, central nervous system tumors, seizures, congenital hydrocephalus, intellectual disability, and Huntington chorea. ${ }^{12}$ In a report from Switzerland, a patient presented with extrapyramidal findings, Gorlin syndrome, and parkinsonism. ${ }^{20}$ However, to the best of our knowledge, there are no reported patients diagnosed with both Gorlin syndrome and congenital mirror movements in the English-language literature. The present patient should remind clinicians once again about the importance of integrative evaluation of patients, with a full physical examination. These individual observations would also be of clinical and molecular importance in elucidating the underlying genetic etiologies of rare conditions.

\section{ACKNOWLEDGMENT}

We thank the patient's family for their contribution to science by giving permission to publish their child's photos, video, and clinical information.

\section{ABBREVIATIONS}

ADM: abductor digiti minimi

DTI: diffusion tensor imaging

fMRI: functional MRI

MEP: motor-evoked potential

TMS: transcranial magnetic stimulation

\section{REFERENCES}

1. Franz EA, Chiaroni-Clarke R, Woodrow S, et al. Congenital mirror movements: phenotypes associated with DCC and RAD51 mutations. J Neurol Sci. 2015;351(1-2): 140-145

2. Farmer SF, Ingram DA, Stephens JA. Mirror movements studied in a patient with Klippel-Feil syndrome. J Physiol. 1990;428:467-484

3. Krams M, Quinton R, Mayston MJ, et al Mirror movements in X-linked Kallmann's syndrome. II. A PET study. Brain. 1997;120 (pt 7):1217-1228

4. Mayston MJ, Harrison LM, Quinton R, Stephens JA, Krams M, Bouloux PM. Mirror movements in X-linked Kallmann's syndrome. I. A neurophysiological study. Brain 1997;120(pt 7):1199-1216

5. Nass R. Mirror movement asymmetries in congenital hemiparesis: the inhibition hypothesis revisited. Neurology. 1985;35(7):1059-1062

6. Ferland RJ, Eyaid W, Collura RV, et al. Abnormal cerebellar development and axonal decussation due to mutations in
AHI1 in Joubert syndrome. Nat Genet. 2004;36(9):1008-1013

7. Högen T, Chan WM, Riedel E, et al. Wildervanck's syndrome and mirror movements: a congenital disorder of axon migration? J Neurol. 2012;259(4):761-763

8. Thapa R, Mukherjee K. Seckel syndrome with asymptomatic tonsillar herniation and congenital mirror movements. J Child Neurol. 2010;25(2):231-233

9. Webb BD, Frempong T, Naidich TP, Gaspar H, Jabs EW, Rucker JC. Mirror movements identified in patients with moebius syndrome. Tremor Other Hyperkinet Mov (N Y). 2014;4:256

10. Gorlin RJ, Goltz RW. Multiple nevoid basal-cell epithelioma, jaw cysts and bifid rib: a syndrome. N Engl J Med. 1960;262:908-912

11. Manfredi M, Vescovi P, Bonanini M, Porter S. Nevoid basal cell carcinoma syndrome: a review of the literature. Int J Oral Maxillofac Surg. 2004;33(2):117-124

12. Lo Muzio L. Nevoid basal cell carcinoma syndrome (Gorlin syndrome). Orphanet J Rare Dis. 2008;3:32

13. Bree AF, Shah MR; BCNS Colloquium Group. Consensus statement from the first international colloquium on basal cell nevus syndrome (BCNS). Am J Med Genet A. 2011;155A(9) :2091-2097

14. Evans DG, Ladusans EJ, Rimmer S, Burnell LD, Thakker N, Farndon PA. Complications of the naevoid basal cell carcinoma syndrome: results of a population based study. J Med Genet. 1993;30(6):460-464

15. Johnson RL, Rothman AL, Xie J, et al. Human homolog of Patched, a candidate gene for the basal cell nevus syndrome. Science. 1996;272(5268):1668-1671

16. Gailani MR, Bale SJ, Leffell DJ, et al. Developmental defects in Gorlin syndrome related to a putative tumor suppressor gene on chromosome 9 . Cell. 1992;69(1):111-117

17. Kimonis VE, Goldstein AM, Pastakia $B$, et al. Clinical manifestations in 105 persons with nevoid basal cell carcinoma syndrome. Am J Med Genet. 1997;69(3):299-308 
18. Galléa C, Popa T, Billot S, Méneret A Depienne C, Roze E. Congenital mirror movements: a clue to understanding bimanual motor control. J Neurol. 2011;258(11):1911-1919
19. Gallea C, Popa T, Hubsch C, et al RAD51 deficiency disrupts the corticospinal lateralization of motor control. Brain. 2013;136 (pt 11): 3333-3346
20. Galati S, Städler C, Möller JC. Parkinsonism and Gorlin-Goltz syndrome: more than an incidental association? J Neuropsychiatry Clin Neurosci. 2015;27(1):e83-e84 


\section{Congenital Mirror Movements in Gorlin Syndrome: A Case Report With DTI and Functional MRI Features}

Erdal Sag, Rahsan Gocmen, F. Gokcem Yildiz, Zeynelabidin Ozturk, Cagri Temucin, Ozlem Teksam and Eda Utine

Pediatrics 2016;137;

DOI: 10.1542/peds.2015-1771 originally published online February 25, 2016;

\begin{tabular}{|c|c|}
\hline $\begin{array}{l}\text { Updated Information \& } \\
\text { Services }\end{array}$ & $\begin{array}{l}\text { including high resolution figures, can be found at: } \\
\text { http://pediatrics.aappublications.org/content/137/3/e20151771 }\end{array}$ \\
\hline References & $\begin{array}{l}\text { This article cites } 17 \text { articles, } 2 \text { of which you can access for free at: } \\
\text { http://pediatrics.aappublications.org/content/137/3/e20151771\#BIBL }\end{array}$ \\
\hline Subspecialty Collections & $\begin{array}{l}\text { This article, along with others on similar topics, appears in the } \\
\text { following collection(s): } \\
\text { Genetics } \\
\text { http://www.aappublications.org/cgi/collection/genetics_sub } \\
\text { Radiology } \\
\text { http://www.aappublications.org/cgi/collection/radiology_sub }\end{array}$ \\
\hline Permissions \& Licensing & $\begin{array}{l}\text { Information about reproducing this article in parts (figures, tables) or } \\
\text { in its entirety can be found online at: } \\
\text { http://www.aappublications.org/site/misc/Permissions.xhtml }\end{array}$ \\
\hline Reprints & $\begin{array}{l}\text { Information about ordering reprints can be found online: } \\
\text { http://www.aappublications.org/site/misc/reprints.xhtml }\end{array}$ \\
\hline
\end{tabular}




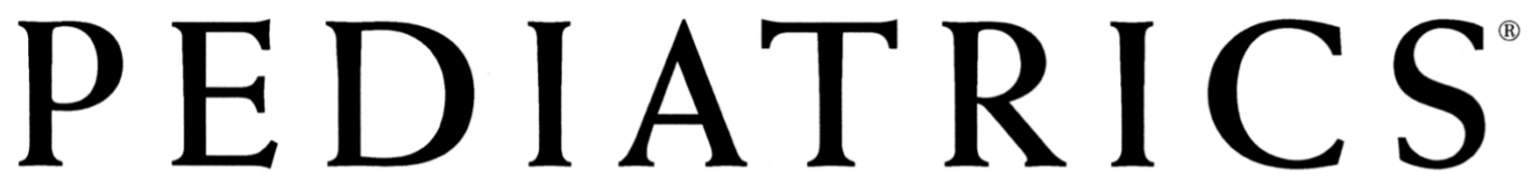

OFFICIAL JOURNAL OF THE AMERICAN ACADEMY OF PEDIATRICS

\section{Congenital Mirror Movements in Gorlin Syndrome: A Case Report With DTI and Functional MRI Features}

Erdal Sag, Rahsan Gocmen, F. Gokcem Yildiz, Zeynelabidin Ozturk, Cagri Temucin, Ozlem Teksam and Eda Utine

Pediatrics 2016;137;

DOI: 10.1542/peds.2015-1771 originally published online February 25, 2016;

The online version of this article, along with updated information and services, is located on the World Wide Web at: http://pediatrics.aappublications.org/content/137/3/e20151771

Data Supplement at:

http://pediatrics.aappublications.org/content/suppl/2016/02/17/peds.2015-1771.DCSupplemental

Pediatrics is the official journal of the American Academy of Pediatrics. A monthly publication, it has been published continuously since 1948. Pediatrics is owned, published, and trademarked by the American Academy of Pediatrics, 141 Northwest Point Boulevard, Elk Grove Village, Illinois, 60007. Copyright $\odot 2016$ by the American Academy of Pediatrics. All rights reserved. Print ISSN: 1073-0397. 